ASTHMA

\title{
Impact of asthma on self-reported health status and quality of life: a population based study of Australians aged 18-64
}

\author{
R D Ampon, M Williamson, P K Correll, G B Marks
}

Thorax 2005;60:735-739. doi: 10.1136/thx.2005.040311

See end of article for authors' affiliations

......................

Correspondence to: Dr G B Marks, Woolcock Institute of Medical

Research, P O Box M77,

Missenden Road,

Camperdown, NSW

2050, Australia;

G.Marks@unsw.edu.au

Received 9 January 2005

Accepted 20 May 2005

\begin{abstract}
Background: The impact of asthma has traditionally been measured in terms of the prevalence of the disease, mortality rates, and levels of healthcare utilisation, particularly hospital admissions. However, the impact of asthma extends beyond these outcomes to include effects on lifestyle, well being, and perceived health status.

Methods: Information on self-reported current asthma status, arthritis and diabetes as well as measures of life satisfaction, self-assessed health status, psychological distress, and interference with usual activities was obtained for 14641 respondents aged 18-64 years in the 2001 National Health Survey of the general population in all states and territories in Australia. Log linear models were fitted separately for each of the dichotomised quality of life measures as dependent variables. The estimates of the adjusted rate ratio obtained from each model were used to compute the population attributable fraction (PAF) of self-reported asthma, arthritis, and diabetes for each of the health status and quality of life measures.

Results: The presence of asthma accounted for $3.18 \%(95 \% \mathrm{Cl} 2.13$ to 4.23$)$ of people reporting poor life satisfaction, $8.12 \%(95 \% \mathrm{Cl} 6.57$ to 9.67$)$ of people reporting poor health status, $5.90 \%(95 \% \mathrm{Cl} 4.19$ to 7.61) of people reporting high psychological distress, and $3.58 \%(95 \% \mathrm{Cl} 2.16$ to 5.01 ) of people reporting any reduced activity days. The proportions of people with these adverse health states attributable to asthma were higher than the proportions attributable to diabetes but lower than the proportions attributable to arthritis.

Conclusion: Asthma is an important contributor to the burden of ill health and impaired quality of life in the community. A strategic approach is needed to develop and implement strategies to address the impact of asthma on quality of life.
\end{abstract}

A sthma is a chronic disease that is prevalent in many developed countries and there is evidence that its prevalence increased in several countries during the latter part of the 20th century, particularly among children. ${ }^{1-4}$ The impact of asthma has traditionally been measured in terms of the prevalence of the disease, mortality rates, and levels of healthcare utilisation, particularly hospital admissions. ${ }^{156}$ However, the impact of asthma extends beyond these outcomes to include effects on lifestyle, well being, and perceived health status. ${ }^{7}$ In order to assess the impact of asthma on quality of life at the population level, it is important to use a comprehensive and valid range of measures of quality of life suitable for implementation in the general population, to have access to a representative sample of the population with and without asthma, and to have information on a range of potential confounding factors. Similar information on the impact of other chronic diseases would assist in interpreting the scale of impact.

The impact of any disease or other factor on the burden of impaired quality of life in the community is a consequence of the extent to which the disease causes impaired quality of life and also the prevalence of the disease in the community. This impact can be quantified as the population attributable fraction (PAF), which represents the proportion of cases of impaired quality of life (or other outcome) that would be avoided if the disease (or other causative factor) was removed or prevented. ${ }^{8}$ It provides a useful indicator of the relative contribution of a particular health state to an outcome measure of interest, and has been used extensively to evaluate the contribution of risk factors to a range of adverse health outcomes. ${ }^{9-12}$ Here we propose the use of PAF as an indicator of the contribution of asthma to adverse quality of life and health status outcomes at a population level.
We have used Australian data from a large nationally representative sample survey to estimate the contribution of asthma to the community wide burden of impairment in quality of life across a number of dimensions including life satisfaction, self-assessed health status, psychological distress, and interference with usual activities. We compared the contribution of asthma with the contribution of two other prevalent chronic diseases-arthritis and diabetes-to provide some context to assist in the interpretation of PAF.

\section{METHODS}

\section{Data source}

The National Health Survey (NHS) is a nationally representative sample survey of adults and children in the general Australian population which is conducted triannually from 2001 by the Australian Bureau of Statistics (ABS). Before this it was carried out on a 6 year cycle: 1989, 1995, 2001. It is a household survey which is completed by trained interviewers and uses a stratified multistage sample of private dwellings. ${ }^{13}$ The analysis was performed using the confidentialised unit record files (CURF) from the 2001 survey provided by the ABS.

The unweighted sample comprised 14641 survey respondents aged 18-64 years. The response rate for the National Health Survey was $92 \%$.

Measures of health status and quality of life The questionnaire included the following four items or groups of items that were relevant to the assessment of health status and quality of life. ${ }^{14}$

Abbreviations: PAF, population attributable fraction 


\begin{tabular}{|llll|}
\hline \multicolumn{2}{|l|}{ Table 1 Categorisation of health status and quality of life outcomes } \\
\hline $\begin{array}{l}\text { Health status and quality } \\
\text { of life outcomes }\end{array}$ & Instrument used & Question responses & Classification \\
\hline Life satisfaction & $\begin{array}{l}\text { Delighted to } \\
\text { terrible scale }\end{array}$ & $\begin{array}{l}\text { Delighted, pleased, or mostly } \\
\text { pleased } \\
\text { Mixed, mostly dissatisfied, } \\
\text { unhappy, or terrible }\end{array}$ & Good \\
Health status & Self-reported & $\begin{array}{l}\text { Excellent, very good, or good } \\
\text { health status } \\
\text { Fair or poor }\end{array}$ & $\begin{array}{l}\text { Good } \\
\text { Poor }\end{array}$ \\
Ksychological distress & Kessler 10 & $\begin{array}{l}\text { Scores of 22-50 } \\
\text { Scores of 10-21 }\end{array}$ & $\begin{array}{l}\text { High } \\
\text { Low to moderate }\end{array}$ \\
\hline
\end{tabular}

- Life satisfaction was measured by a single question: "How do you feel about your life as a whole, taking into account what has happened in the last year and what you expect to happen in the future?" Responses ranged from "delighted" to "terrible" on a 7 point Likert scale that provides a general indicator of satisfaction with life. Previous work has shown that the Delighted-Terrible life satisfaction scale has high validity and discriminative power in large population based studies. ${ }^{15}$

- Self-assessed health status was measured by a single question: "In general, would you say that your health is excellent, very good, good, fair or poor?". ${ }^{13}{ }^{17}$ The validity of this measure is supported by a 7 year follow up study of elderly persons which found that self-rated health was predictive of survival. ${ }^{17}$

- A 10-item scale measuring psychological distress (Kessler 10): "In the past 4 weeks, about how often did you feel (tired for no good reason, nervous, hopeless, restless or fidgety, depressed, sad, worthless, etc)?" This measures the level of symptoms of anxiety and depression experienced in the 4 weeks prior to interview. ${ }^{18}{ }^{19}$ Furukawa et al showed that the K10 scales outperformed the General Health Questionnaire in screening for psychological distress at a population level. ${ }^{18}$

- A two-question measure of "any reduced activity days" based on answers to the questions: "In the last 2 weeks, have you stayed away from your (work/school/place of study) for more than half the day because of any illness or injury you had?" and "On any (other) days in the last 2 weeks, have you had to cut down on anything you usually do because of these illnesses or injuries?". ${ }^{14}$

Table 1 presents the classification of the first three measures used in this study.

\section{Classification of conditions and confounders}

For this analysis, subjects were classified as having current asthma if they responded positively to both of the following questions: "Have you ever been told by a doctor or nurse that you have asthma?" and "Do you still get asthma?". All other subjects were classified as not having current asthma. Subjects were classified as having diabetes if they responded positively to the question "Have you ever been told by a doctor or a nurse that you have diabetes?". ${ }^{14}$ Subjects were classified as having arthritis if they responded positively to the question "Do you currently have osteoarthritis; rheumatoid arthritis; gout; rheumatism; other type of arthritis; and other arthropathies?" Information on the following potential confounding factors, available from the questionnaire, were also used in the analysis: age group (18-34, 35-54, and 5564 years), sex, quintiles of socioeconomic status of area of residence using the Index of Relative Socio-Economic Disadvantage (SEIFA), ${ }^{20}$ smoking status, and body mass index (BMI). The last of these was defined as underweight (BMI $<18.5 \mathrm{~kg} / \mathrm{m}^{2}$ ), overweight $\left(\right.$ BMI $\geqslant 25 \mathrm{~kg} / \mathrm{m}^{2}$ ), or normal based on self-reported height and weight.

\section{Statistical analysis}

We estimated the rate ratio of self-reported current asthma, diabetes, and arthritis for having each of the quality of life outcomes. Log linear models were fitted separately for each of the dichotomised quality of life measures as dependent variables. For each of these, separate models were fitted in which self-reported asthma, diabetes, and arthritis were respectively included as the independent variable of interest. All the potential confounders listed above were also included in all the models. Smoking status and sex were also tested as potential modifiers of the effect of asthma on the quality of life outcomes using interaction terms. A Poisson regression model was used with the time-at-risk value specified as 1 to allow the estimation of adjusted rate ratios as the exponent of the coefficient of interest. The regression was adjusted for regional strata (major cities, inner regional and outer areas) and weighted by reference to the population age and sex distribution. ${ }^{21}{ }^{22}$ All analyses were performed using STATA version 7.0 (StataCorp, College Station, TX, USA, 2001) and the weighted ABS NHS-CURF data. PAF and its corresponding $95 \%$ confidence interval were computed using the formulae for this parameter and its variance suggested by Walter: ${ }^{8}$

$$
P A R=\frac{P_{e}^{*}(a R R-1)}{P_{e}{ }^{*}(a R R-1)+1}
$$

where $P_{e}=$ proportion of population exposed to the risk (that is, prevalence of asthma) and $a R R=$ adjusted rate ratio of the exposure (asthma).

\section{RESULTS}

There were 1674 respondents aged 18-64 years with current asthma. After adjustment for the sampling design, the prevalence of asthma in this age range was estimated to be $11.2 \%$ (95\% confidence interval (CI) 10.6 to 11.8 ). Among 14641 respondents, there were missing data on BMI for 1196 and missing data on SEIFA quintile for 17. Hence, the available sample size for the multivariate analysis was 13428 .

The prevalence of adverse outcomes in all four quality of life related measures was significantly higher in subjects with current asthma than in those without current asthma (table 2). Smoking status did not significantly modify the effect of asthma on any of the quality of life outcomes (all $p>0.05)$. The effect of asthma on self-assessed health status differed between men and women $(p=0.03)$. However, the difference in estimates of rate ratio was relatively small 
Table 2 Prevalence of adverse outcomes by asthma status in adults aged 18-64 years in Australia, 2001 ( $n=14641$ )

\begin{tabular}{lllll}
\hline Asthma status & $\begin{array}{l}\text { Poor life } \\
\text { satisfaction }\end{array}$ & $\begin{array}{l}\text { Poor self-assessed } \\
\text { health }\end{array}$ & $\begin{array}{l}\text { High psychological } \\
\text { distress }\end{array}$ & $\begin{array}{l}\text { Any reduced } \\
\text { activity days }\end{array}$ \\
\hline $\begin{array}{l}\text { Current asthma } \\
\%(95 \% \mathrm{Cl})\end{array}$ & $30.9(28.3$ to 33.6$)$ & $25.6(23.1$ to 28.0$)$ & $20.8(18.5$ to 23.1$)$ & $22.4(20.1$ to 24.7$)$ \\
$\begin{array}{l}\text { No current asthma } \\
\%(95 \% \mathrm{Cl})\end{array}$ & $23.6(22.8$ to 24.5$)$ & $14.7(14.0$ to 15.4$)$ & $12.3(11.6$ to 13.0$)$ & 16.3 (15.6 to 17.1) \\
\hline
\end{tabular}

(adjusted rate ratio 1.53 for men and 1.99 for women) and the data for men and women were combined for further analysis. Sex did not modify the effect of asthma on the other quality of life outcomes (all $\mathrm{p}>0.05$ ).

After adjustment for confounding factors, the rate ratio of asthma for having adverse quality of life outcomes ranged from 1.3 for the life satisfaction scale to 1.8 for self-assessed health status (table 3, row 1). The effect of asthma status on each of these attributes was statistically significant $(p<0.05)$.

The presence of asthma accounted for $3.18-8.12 \%$ of people reporting adverse quality of life or health status outcomes (table 4, row 1). The proportions of people with poor life satisfaction, poor self-assessed health status, high psychological distress, and reduced activity days attributable to asthma were higher than the proportions of people with these adverse health states attributable to diabetes but lower than the proportions attributable to arthritis (table 4).

\section{DISCUSSION}

This survey has shown that adults of working age with asthma have poorer health status and quality of life outcomes than those with no asthma. This effect is independent of confounding by sociodemographic and life style factors and is evident across a range of dimensions of quality of life. In comparison with two other chronic health conditions, asthma has a larger adverse impact on health status and quality of life than diabetes but less impact than arthritis. These differences are largely due to the relative prevalence of the three conditions; the adjusted rate ratios for adverse quality of life outcomes were similar for the three conditions.

The findings are based on a survey conducted among a large nationally representative sample of the Australian population with a high participation rate and, hence, can be regarded as generalisable to persons with asthma in the broader community.

Population monitoring of quality of life outcomes presents inherent difficulties because quality of life cannot be directly measured. The broad range of outcomes used here represents an attempt to identify consistent trends in the associations of asthma with several disparate outcomes that can be regarded as relevant to quality of life. It is possible that these elements do not fully represent an individual's quality of life. Furthermore, it is likely that there was substantial individual variation in the interpretation of these concepts by the survey participants and that this would have influenced how they responded. Nonetheless, the consistency across a broad range of outcome measures in this study strongly suggests that asthma does have an important impact on the lives of those affected.

PAF is a valuable tool for describing the relative contribution of various risk factors or exposures to the aetiology of health states or diseases. This is achieved by combining information on the strength of the association between the risk factor and the outcome, measured as rate ratio, with data on the prevalence of the risk factor. In this instance, we have regarded the various adverse quality of life related states as the outcomes for which risks are being evaluated and the presence of asthma, or other specified chronic diseases, as the potential risk factors for those outcomes.

PAF is interpreted as the extent to which a disease or health state could be avoided by the removal of a specified risk factor. ${ }^{823}$ This interpretation is based on the assumption that the observed associations are causal. ${ }^{23}$ This is an assumption that cannot be directly tested in a cross sectional observational study. However, the availability of data on sociodemographic and life style factors, which we have incorporated into the multivariate model, has reduced the risk that the observed associations are attributable to confounding.

The validity of the attribution of adverse health status and quality of life outcomes to asthma is partly dependent on the validity of the method used to identify cases of asthma in the study population. In this survey, self-reported, doctor diagnosed current asthma was used as the indicator of the presence of this health condition. This question is derived from the ATS-DLD-78 Adult Respiratory Questionnaire. ${ }^{24}$ As there is no gold standard criterion for asthma, it has proved difficult to estimate accurately the validity of this question for

Table 3 Prevalence and crude and adjusted ${ }^{*}$ rate ratio of three health conditions for four adverse quality of life outcomes, Australia, 2001

\begin{tabular}{|c|c|c|c|c|c|}
\hline & $\begin{array}{l}\text { Prevalence } \\
(95 \% \mathrm{Cl})\end{array}$ & $\begin{array}{l}\text { Poor life } \\
\text { satisfactiont }\end{array}$ & $\begin{array}{l}\text { Poor self-assessed } \\
\text { health } \dagger\end{array}$ & $\begin{array}{l}\text { High psychological } \\
\text { distresst }\end{array}$ & $\begin{array}{l}\text { Any reduced } \\
\text { activity days } †\end{array}$ \\
\hline \multirow[t]{3}{*}{ Asthma } & $n=1674$ & 1.31 & 1.74 & 1.69 & 1.37 \\
\hline & 11.2 & 1.29 & 1.79 & 1.56 & 1.33 \\
\hline & (10.6 to 11.9 ) & (1.17 to 1.43 ) & $(1.60$ to 2.00$)$ & (1.37 to 1.77 ) & (1.18 to 1.50$)$ \\
\hline \multirow[t]{3}{*}{ Arthritis } & $n=2524$ & 1.68 & 2.77 & 1.75 & 1.69 \\
\hline & 16.2 & 1.57 & 2.13 & 1.86 & 1.82 \\
\hline & (15.5 to 16.9 ) & (1.45 to 1.69 ) & (1.93 to 2.34 ) & (1.66 to 2.08 ) & (1.65 to 2.01 ) \\
\hline \multirow[t]{3}{*}{ Diabetes } & $n=497$ & 1.30 & 2.97 & 1.59 & 1.39 \\
\hline & 3.4 & 1.16 & 2.25 & 1.67 & 1.45 \\
\hline & (3.1 to 3.8 ) & (0.98 to 1.37$)$ & (1.96 to 2.58 ) & (1.35 to 2.07 ) & (1.19 to 1.77 ) \\
\hline
\end{tabular}

*Adjusted for age group, sex, smoking status, socioeconomic status, and body mass index.

†Data presented as crude rate ratio $(n=14641)$, adjusted rate ratio $(n=13428)$, and $95 \% \mathrm{Cl}$ of adjusted rate ratio. 
Table 4 Crude and adjusted* population attributable fraction (PAF) of three health conditions for four adverse quality of life outcomes, Australia, 2001

\begin{tabular}{|c|c|c|c|c|}
\hline & Poor life satisfaction† & Poor self-assessed health $\dagger$ & High psychological distress $†$ & Any reduced activity days $\uparrow$ \\
\hline Asthma & $\begin{array}{l}3.36 \\
3.18 \\
(2.13 \text { to } 4.23)\end{array}$ & $\begin{array}{l}7.72 \\
8.12 \\
(6.57 \text { to } 9.67)\end{array}$ & $\begin{array}{l}7.23 \\
5.90 \\
(4.19 \text { to } 7.61)\end{array}$ & $\begin{array}{l}4.02 \\
3.58 \\
\text { (2.16 to } 5.01)\end{array}$ \\
\hline Arthritis & $\begin{array}{l}10.26 \\
8.40 \\
(6.98 \text { to } 9.82 \text { ) }\end{array}$ & $\begin{array}{l}22.96 \\
15.44 \\
(13.34 \text { to } 17.55)\end{array}$ & $\begin{array}{l}11.20 \\
12.16 \\
(10.01 \text { to } 14.31)\end{array}$ & $\begin{array}{l}10.39 \\
11.77 \\
(9.90 \text { to } 13.65)\end{array}$ \\
\hline Diabetes & $\begin{array}{l}1.03 \\
0.55 \\
(-0.01 \text { to } 1.10)\end{array}$ & $\begin{array}{l}6.37 \\
4.13 \\
(3.11 \text { to } 5.15)\end{array}$ & $\begin{array}{l}2.00 \\
2.27 \\
(1.37 \text { to } 3.17)\end{array}$ & $\begin{array}{l}1.39 \\
1.53 \\
(0.79 \text { to } 2.26)\end{array}$ \\
\hline
\end{tabular}

${ }^{*}$ Adjusted for age group, sex, smoking status, socioeconomic status, and body mass index.

†Data presented as crude PAF $(n=14641)$, adjusted PAF $(n=13428)$, and $95 \% \mathrm{Cl}$ of adjusted PAF.

measuring asthma. Nevertheless, it is known that the clinical manifestations of chronic obstructive pulmonary disease (COPD) and asthma overlap and the conditions may coexist. COPD has a substantial adverse impact on quality of life. ${ }^{25} 26$ Among subjects aged 50-64 within this study population, this overlap and misclassification may have influenced the estimates of the impact of asthma.

Comparison among the quality of life related outcomes is informative. The impact of asthma on life satisfaction, while significant, was less than the impact of asthma on the other health status outcomes. Life satisfaction is probably influenced by a broader range of factors than those that affect self-perceived health status, distress, and disability outcomes. For this reason, it is not surprising that the proportion of variation in life satisfaction that can be attributed to the presence of asthma is relatively small.

The findings in this survey extend previous observations that people with asthma have impaired quality of life. ${ }^{72}$ Adams et al, ${ }^{27}$ using data for the SF-36 physical and mental component summary scores from the North West Adelaide Health Study $(\mathrm{N}=2523)$, showed that quality of life was more impaired in people with asthma than in those who did not have the disease. Similar findings were reported in the Behavioral Risk Factor Surveillance System (BRFSS) in the USA. $^{7}$ However, unlike the present study, most previous studies have not attempted to quantify the relative impact of chronic disease in terms of population attributable risk.

Asthma is an important contributor to the burden of ill health and impaired quality of life in the community, having impacts on measures of physical, psychological, and social functioning and well being. This impact extends beyond that measured by conventional indices of physiological status and healthcare utilisation. Further work is needed to develop a framework of interventions that will help decrease the burden of the disease, thus reducing its impact on people's quality of life. Currently, there are no interventions that have been shown to substantially reduce the incidence, and hence the prevalence, of asthma. The health system must therefore look for opportunities to ensure that asthma is being effectively managed in the community, and that those with asthma are offered strategies to minimise its impact on their quality of life.

\section{ACKNOWLEDGEMENTS}

The authors thank Ms Leanne Poulos for reviewing the first drafts of the paper and the Australian Bureau of Statistics as the official custodian of the National Health Survey confidentialised unit record files.

\section{Authors' affiliations}

R D Ampon, M Williamson, P K Correll, G B Marks, Australian Centre for Asthma Monitoring, a Collaborating Unit of the Australian Institute of Health and Welfare, Camperdown, NSW 2050, Australia
G B Marks, Woolcock Institute of Medical Research, University of Sydney, Sydney, NSW 2006, Australia

M Williamson, Centre for Health Informatics, University of New South Wales, Sydney, NSW 2052, Australia

The Australian Centre for Asthma Monitoring (ACAM) is a collaborating unit of the Australian Institute of Health and Welfare funded as part of the Australian Government's initiative to establish and maintain the Australian System for Monitoring Asthma.

\section{REFERENCES}

1 Australian Centre for Asthma Monitoring. Asthma in Australia 2003. Asthma Series 1. AlHW Cat. No. ACM 1. Canberra: Australian Institute of Health and Welfare, 2003.

2 Downs SH, Marks GB, Sporik R, et al. Continued increase in the prevalence of asthma and atopy. Arch Dis Child 2001;84:20-3.

3 Raj A, Mishra A, Feinsilver $\mathrm{SH}$, et al. An estimate of the prevalence and impact of asthma and related symptoms in a New York City middle school. Chest 2000;118:84S

4 Soriano JB, Kiri VA, Maier WC, et al. Increasing prevalence of asthma in UK primary care during the 1990s. Int J Tuberc Lung Dis 2003;7:415-21.

5 Turk A. Understanding the impact of asthma in the $21^{\text {st }}$ century. J Manag Care Pharm 2002;8(5 Suppl):3-7

6 Sullivan SD. Asthma in the United States: recent trends and current status. J Manag Care Pharm 2003;9(5 Suppl):3-7.

7 Ford ES, Mannino DM, Homa DM, et al. Self-reported asthma and healthrelated quality of life: findings from the behavioral risk factor surveillance system. Chest 2003;123:119-27.

8 Walter SD. Calculation of attributable risks from epidemiological data. Int J Epidemiol 1978;7:175-82.

9 Deubner DC, Wilkinson WE, Helms MJ, et al. Logistic model estimation of death attributable to risk factors for cardiovascular disease in Evans County, Georgia. Am J Epidemiol 1980;1 12:135-43.

10 Dwyer T, Ponsonby AL, Gibbons LE, et al. Prone sleeping positions and SIDS: evidence from recent case-control and cohort studies in Tasmania. J Paediatr Child Health 1991;27:340-3.

11 Garcia-Martin M, Lardelli-Claret P, Jimenez-Moleon JJ, et al. Proportion of hospital deaths potentially attributable to nosocomial infection. Infect Control Hosp Epidemiol 2001;22:708-14.

$12 \mathrm{He} \mathrm{J,} \mathrm{Ogden} \mathrm{LG,} \mathrm{Bazzano} \mathrm{LA,} \mathrm{et} \mathrm{al.} \mathrm{Risk} \mathrm{factors} \mathrm{for} \mathrm{congestive} \mathrm{heart} \mathrm{failure} \mathrm{in}$ US men and women: NHANES I epidemiologic follow-up study. Arch Intern Med 2001;161:996-1002.

13 Australian Bureau of Statistics. 2001 National Health Survey: user's guide, Cat.No.4363.0.55.001. Canberra: Australian Bureau of Statistics, 2001

14 Australian Bureau of Statistics. Information Paper: 2001 National Health Survey: survey questionnaires. Canberra: Australian Bureau of Statistics, 2001.

15 Dear K, Henderson S, Korten A. Well-being in Australia: findings from the National Survey of Mental Health and Well-being. Soc Psychiatry Psychiatr Epidemiol 2002;37:503-9.

16 Cummins RA. On the trail of the gold standard for subjective well-being. Soc Indicators Res 1995;35:179-200.

17 McCallum J, Shadbolt B, Wang D. Self-rated health and survival: a 7-year follow-up study of Australian elderly. Am J Public Health 1994:84:1100-5.

18 Furukawa TA, Kessler RC, Slade T, et al. The performance of the K6 and K10 screening scales for psychological distress in the Australian National Survey of Mental Health and Well-being. Psychol Med 2003;33:357-62.

19 Australian Bureau of Statistics. Information Paper: Use of the Kessler psychological distress scale in ABS health surveys. Cat. No. 4817.0.55.001. Canberra: Australian Bureau of Statistics, 2001.

20 Australian Bureau of Statistics. Information Paper: 1996 Census of population and housing: socio-economic indexes for areas, Cat.No.2039.0. Canberra: Australian Bureau of Statistics, 1998.

21 Barros A, Hirakata VN. Alternatives for logistic regression in cross-sectional studies: an empirical comparison of models that directly estimate the prevalence ratio. BMC Med Res Methodol 2003;3(21). 
22 McNutt LA, Wu C, Xue X et al. Estimating the relative risk in cohort studies and clinical trials of common outcomes. Am J Epidemiol 2003; 157:940-3.

23 Rockhill B, Newman B, Weinberg C. Use and misuse of population attributable fractions. Am J Public Health 1998:88:15-9.

24 Ferris BG. Epidemiology Standardization Project (American Thoracic Society). Am Rev Respir Dis 1978;118:1-120.
25 Curtis J, Hudson L, Deyo R. Health-related quality of life among patients with chronic obstructive pulmonary disease. Thorax 1994;49:162-70.

26 Okubadejo A, Jones P, Wedzicha J. Quality of life in patients with chronic obstructive pulmonary disease and severe hypoxaemia. Thorax 1996:51:44-7.

27 Adams RJ, Wilson DH, Appleton S, et al. Underdiagnosed asthma in South Australia. Thorax 2003;58:846-50.

\section{LUNG ALERT}

Monitoring exhaled nitric oxide to guide inhaled steroid dosage in asthma

$\Delta$ Smith $A D$, Cowan JO, Brassett KP, et al. Use of exhaled nitric oxide measurements to guide treatment in chronic asthma N Engl J Med 2005;352:2163-73

The method of measuring sputum eosinophils and airway hyperresponsiveness to aid clinicians to titrate anti-inflammatory therapy for asthma has previously been described. However, measuring these biomarkers can be cumbersome and time consuming.

Smith et al evaluated whether exhaled nitric oxide (NO)—which can be quickly and easily measured with no discomfort to the patient - can help to identify optimum inhaled corticosteroid doses. Ninety seven asthmatics were randomised into a 1 year single blind, placebo controlled trial. Individuals had their inhaled corticosteroid dose altered at regular intervals, either on the basis of conventional parameters alone or with knowledge of their exhaled NO concentration. At the end of the study the mean daily dose of fluticasone was $370 \mu \mathrm{g}$ in the NO group compared with $641 \mu \mathrm{g}$ in the control group $(\mathrm{p}=0.003$ for the difference). No significant differences were observed in exacerbations, lung function, or sputum eosinophils.

The authors conclude that, with the help of exhaled NO measurements, inhaled corticosteroid doses can be successfully titrated down without loss of asthma control. This study raises the possibility that this easy-to-measure surrogate inflammatory biomarker can successfully tailor the inhaled corticosteroid dose in "real life" and, in turn, minimise potential local and systemic adverse sequelae. This may result in conventional parameters alone-which tend to be dissociated from the asthmatic inflammatory process-playing less of a central role.

G P Currie Specialist Registrar, Department of Respiratory Medicine, Aberdeen Royal Infirmary, Foresterhill, Aberdeen AB25 2ZN, UK; graeme.currie@nhs.net 